\title{
Improving the numerical prediction of a cyclone in the Mediterranean by local potential vorticity modifications
}

\author{
Sébastien Argence ${ }^{\mathrm{a}, \mathrm{b} *}$, Dominique Lambert ${ }^{\mathrm{a}}$, Evelyne Richard ${ }^{\mathrm{a}}$, Jean-Pierre Chaboureau ${ }^{\mathrm{a}}$, \\ Philippe Arbogast ${ }^{\mathrm{c}}$ and Karine Maynard ${ }^{\mathrm{c}}$ \\ ${ }^{a}$ Laboratoire d'Aérologie CNRS UMR 5560, Université de Toulouse, Toulouse, France \\ ${ }^{\mathrm{b}}$ Numtech, Aubière, France \\ ${ }^{\mathrm{c}}$ Météo-France, Toulouse, France
}

\begin{abstract}
This study explores the benefit that can be drawn from incorporating local potential vorticity (PV) modifications into a numerical forecast. The case under study is the severe cyclogenesis that occurred in the Western Mediterranean from 9 to 12 November 2001. This case was shown to be extremely sensitive to the upper-level flow, which governed to a great extent the deepening of the depression and the location and intensity of its associated precipitation. Corrections of PV were guided by METEOSAT-7 water vapour observations and restricted to the upper troposphere, mainly altering the topography of the dynamical tropopause. Using both the French operational global model ARPEGE and the non-hydrostatic mesoscale model Meso-NH, it is shown that carefully designed PV corrections lead to a substantial improvement in the simulation of the storm, both in terms of surface pressure, cloud cover and precipitation forecasts. Furthermore, the impact of the modifications is shown to be a maximum when they are introduced at the time corresponding to the incipient stage of cyclogenesis.
\end{abstract}

KEY WORDS PV inversion; METEOSAT-7 water vapour imagery; mesoscale dynamics

\section{Introduction}

Despite continuous improvements in numerical weather forecasting systems, some extreme weather events still remain hardly predictable even at very short range. One of the most typical examples is the 'Christmas storm' which struck Western Europe on 27 December 1999. This powerful cyclone was poorly predicted by several operational meteorological centres, including Météo-France, the European Centre for Medium-range Weather Forecasting (ECMWF) and the UK Met Office (Baleste et al., 2001). The forecast skill in such cases is limited by the quality of the initial conditions, themselves strongly sensitive to the density of observations and to the data assimilation system, which may reject correct values if they differ too much from the background field. In this context, human intervention appears to be essential to monitor and, if necessary, modify numerical outputs by comparing them with the latest observations.

This paper deals with a method that allows a forecaster to modify a numerical output in near-real time in case of discrepancy with observational data. The decision whether to modify a numerical analysis or a forecast is based on comparisons between PV fields and water vapour (WV) images taken from geostationary satellites

\footnotetext{
${ }^{*}$ Correspondence to: Sébastien Argence, Numtech, 6 Allée Alan Turing, Parc Technologique de La Pardieu, BP 30242, Aubière Cedex, France. E-mail: sebastien.argence@numtech.fr
}

(e.g. METEOSAT-7 on bandwidth $5.7-7.1 \mu \mathrm{m}$ ). As the WV channel is mainly affected by the humidity and the temperature near the tropopause level, it is possible, under some assumptions, to relate dark and bright features of WV images to relevant PV anomalies. Therefore, in the case of a mismatch between analyzed or forecasted PV fields and WV images, PV modifications may be applied according to the observations to improve the numerical outputs.

Some previous studies (e.g. Demirtas and Thorpe, 1999; Hello and Arbogast, 2004; Guerin et al., 2006; Røsting and Kristjánsson, 2006, 2008; Manders et al., 2007) have shown that initial conditions corrected by PV modifications according to WV imagery may lead to substantial reduction of the forecast errors. In these earlier investigations, the authors placed special emphasis on deep North Atlantic cyclones that were poorly forecast by operational meteorological centres. However, considering a set of five different North Atlantic cyclonic systems, Swarbrick (2001) stressed the subjective nature of the approach and showed that the usefulness of the PV-WV relationship for initial conditions modifications purpose was strongly dependent on the type of case study he considered. To get the method more objective, Røsting and Kristjánsson $(2006,2008)$ combined singular vectors informations and PV-WV comparisons to optimize the horizontal and vertical structures of the initial PV modifications they applied on a selection of severe winter storms that struck Western Europe in 1999, 2000 and 
2007. Nevertheless, a far greater number of case-studies is still needed to assess the usefulness of the method for an operational use.

To our knowledge, few studies have transposed the concept of the PV-WV relationship to severe weather events in the Mediterranean (e.g. Georgiev, 1999; Lagouvardos and Kotroni, 2000; Georgiev and Martín, 2001). While Georgiev (1999) tried to quantify the relationship between METEOSAT WV data and positive PV anomalies (he found a correlation coefficient ranging between 0.58 and 0.64 considering $500 \mathrm{hPa} \mathrm{PV}$ analyses for two cases of cyclones), Georgiev and Martín (2001) used the PV-WV link as a diagnostic tool to validate numerical outputs. Nevertheless, none of these studies used PV inversion methods to correct numerical PV fields in the case of a mismatch with satellite data. As most heavy Mediterranean rainfall events are associated with positive PV anomalies at the tropopause (Chaboureau and Claud, 2006; Funatsu et al., 2008), it would be interesting to apply such a correction procedure to some typical Mediterranean cases. Furthermore, since Mediterranean storms are generally of lower horizontal scale than Atlantic depressions and may involve different physical processes (e.g. the local influence of orographic forcing), it would be a challenging task to investigate the impact of local PV modifications on the forecast of mesoscale phenomena such as deep convection and heavy precipitation that commonly occurred in the Mediterranean.

In the present work, we made an attempt to apply PV corrections guided by METEOSAT-7 WV imagery to a case of intense cyclogenesis in the Western Mediterranean. This event was shown to be extremely sensitive to the upper-level dynamics (Romero, 2008; Argence et al., 2008) and air-sea exchanges (Tripoli et al., 2005). In particular, Argence et al. (2008) demonstrated that minor initial perturbations in the depth of the upper-level trough (and the intensity of the associated positive PV anomaly) at the initial stage of cyclogenesis could propagate and intensify during numerical simulations, strongly impacting the surface cyclone forecast. A close inspection of the ARPEGE (Action de Recherche Petite Echelle Grande Echelle; Courtier et al., 1991) analysis of 9 November 2001 at 1200 UTC revealed a rather clear mismatch between upper-level PV fields and METEOSAT-7 WV observations. The operational ARPEGE forecast starting from this analysis performed poorly in simulating the deepening rate of the cyclone and its associated rainfall. Here, we will discuss some PV modifications that improved the correspondence between PV fields and METEOSAT-7 WV imagery and their impact on the forecast of the cyclone and its associated precipitation.

In section 2, we recall some basic ideas concerning the PV-WV relationship and describe the methodology employed for incorporating local PV modifications in numerical outputs. In section 3, the selected case study is described. Experiments based on PV modifications and conducted with the global ARPEGE model are discussed in section 4. The impact of applying PV corrections is further assessed through cloud-resolving simulations using the non-hydrostatic Meso-NH model (Lafore et al.,
1998) in section 5. Discussion of the robustness of the $\mathrm{PV}$ modification approach and some conclusions are to be found in sections 6 and 7 respectively.

\section{Methodology}

\subsection{Basis of the PV-WV relationship}

Through the conservation and invertibility principles, the PV provides meaningful information about upper-level dynamics, particularly relevant for the understanding of midlatitude cyclone development (Hoskins et al., 1985). The assumptions of balance in the atmosphere and uniform tropospheric PV make it possible to use only the level of the dynamical tropopause to diagnose upper-level dynamics (Santurette and Joly, 2002). The dynamical tropopause is the region in which PV increases rapidly from 1 to 3 PVU (Potential Vorticity Unit; 1 $\left.\mathrm{PVU}=10^{-6} \mathrm{~K} \mathrm{~m}^{-2} \mathrm{~s}^{-1} \mathrm{~kg}^{-1}\right)$. One way of diagnosing it is through the use of maps of the 1.5 PVU surface or PV fields on a specific isentropic or isobaric surface (generally between 300 and $400 \mathrm{hPa}$ ).

The METEOSAT-7 WV channel, centred on the $6.3 \mu \mathrm{m}$ absorption band, is sensitive to the absorption of the infrared emission from the Earth's surface and clouds by the WV in the middle and upper troposphere (between approximately 300 and $500 \mathrm{hPa}$ ). The WV channel radiation reaching the satellite is mainly affected by the WV content on the radiation path, the vertical location of the $\mathrm{WV}$ and its temperature. It is recognized that, in baroclinic zones, there is a close correspondence between dark (bright) features in the WV images and positive (negative) PV anomalies (e.g. Mansfield, 1996). Therefore, a dry intrusion of stratospheric origin that penetrates downward into the upper troposphere corresponds to high brightness temperatures (dark area on WV imagery). Such intrusions can generally be related to positive PV anomalies since stratospheric air is characterized by high PV values. Conversely, ascending motion downstream of a dry intrusion advects moist air of low to mid-level origin towards the upper troposphere and produces bright patterns on WV images that correspond to high tropopause levels (and subsequent negative PV anomalies). A sharp transition between light and dark shades in the WV brightness temperatures would reveal a region in which the dynamical tropopause sloped steeply and would be associated with large horizontal gradients of PV near the tropopause level.

As the comparison only works well in dynamical regions, there is no simple one-to-one relationship between upper-level PV structures and WV radiances. The relationship may depend on the temperature profile in the path of the WV channel radiation, the latitude and the season. In particular, the following limitations must be taken into account:

- Dark zones are not always connected with PV anomalies. Stratospheric intrusions only occur in the vicinity of the jet, so the relation between PV and dark areas is valid only in this vicinity, on its polar side. In fact, on the equatorward side of the polar front, relatively high-radiance regions are not 
related to PV anomalies but are a consequence of higher temperatures of the atmospheric columns in air masses of tropical origin.

- Mid-level PV anomalies may not be associated with dry zones on WV images.

- In the polar region in winter, the lower atmosphere is so cold that low-tropopause regions may appear as light grey shades on WV pictures.

A thorough review of the combined use of WV imagery and PV analysis can be found in Santurette and Georgiev (2005).

\subsection{Building corrections in a numerical output}

The modifications applied to numerical outputs are based on comparisons between METEOSAT-7 WV images and PV fields displayed on isobaric surfaces chosen to intersect the dynamical tropopause where its topography varies rapidly (roughly between 300 and $400 \mathrm{hPa}$ for the case under study). A common way to incorporate 'dynamical corrections' into a numerical output is to apply PV modifications considering the invertibility principle, which asserts that the state of the atmosphere can be recovered within a given balance condition, knowing the PV field and boundary conditions. We proceeded as follows:

- Compare upper-tropospheric PV fields with METEOSAT-7 WV brightness temperatures at specific times.

- In the case of a mismatch, modify the PV field according to the METEOSAT-7 WV information.

- Perform a numerical rerun based on the subjectively improved numerical output.

In case of a PV-WV mismatch, we had the possibility of adding/subtracting PV structures and shifting them to obtain a better visual correlation between PV fields and METEOSAT-7 WV brightness temperatures. To isolate sub-structures of interest, we applied temporal filtering to the analyzed PV fields. Gaussian-type temporal filtering was used on the sequence of PV fields covering a 4-day period. The filtering was centred on the time corresponding to the PV-WV comparison. When the structures of interest had been extracted from the original numerical output, they could be manipulated in such a way that upper-level PV fields fit well with the WV observations. The modified PV anomalies were then inverted (in terms of geopotential heights, wind and temperature fields) and incorporated into the numerical output following the PV inversion method presented by Arbogast et al. (2008). The modifications performed in this study were restricted to the region between 150 and $500 \mathrm{hPa}$ to focus the corrections on the tropopause topography. A detailed description of the different experiments is presented in the following sections.

\section{Case-study}

The present work focuses on the powerful storm that struck North Africa and the Balearic Islands from 9 to 12 November 2001. This severe storm caused many deaths in Algeria and huge damage in North Africa and Mallorca. The choice of this event was motivated by the complex nature of the meteorological situation wherein it occurred. This event was associated with an upper-level blocking circulation that formed as a result of upperlevel anticyclogenesis over Western Europe (Santurette and Georgiev, 2005), thus making difficult an accurate prediction of the storm life cycle. Moreover, to our knowledge, this work was the first one dealing with initial PV modifications for such a complex case of blocking regime.

The different phases of the storm development were identified through a study of operational ARPEGE analyses (Figure 1). On 9 November 2001 at 1200 UTC (Figure 1(a)), the first sign of storm initiation was an area of ascending motion at $38^{\circ} \mathrm{N}$ just ahead of an upperlevel trough characterized by a lowering of the dynamical tropopause (surface of PV equal to 1.5 PVU). In the morning of 10 November 2001 (Figures 1(b) and (c)), surface cyclogenesis developed over North Africa in association with a southeastward shift of the upper-level low. During this phase, strong convection occurred along the Algerian coasts and was followed by heavy flooding in the Algiers area. Thereafter, the cyclone took a northerly trajectory and reached its maximum deepening on 11 November 2001 at 0000 UTC (Figure 1(d)), just before striking the Balearic islands with $10 \mathrm{~m}$ wind gusts exceeding $40 \mathrm{~m} \mathrm{~s}^{-1}$. For complementary details about the life cyle of the cyclonic system studied in this paper, the reader can be referred to Santurette and Georgiev (2005) who provided a very comprehensive description of this case-study by analyzing METEOSAT-7 WV observations together with numerical operational analysis.

\section{ARPEGE experiments}

In this section, we will study the behaviour of various forecasts in response to local PV modifications. Numerical experiments were performed with the Météo-France ARPEGE operational forecasting system. It was run at a T358 horizontal resolution with 41 vertical levels. The horizontal grid spacing was about $25 \mathrm{~km}$ over Western Europe and the Western Mediterranean. Table I summarizes the characteristics of the different ARPEGE experiments. The most relevant phenomena related to the event under study will be stressed, i.e. the heavy precipitation in the morning of 10 November 2001 and the deep surface cyclone on 11 November 2001 at 0000 UTC.

4.1. Forecast starting from the operational analysis of 9 November 2001 at 1200 UTC: arpoper

Figures 2(a) and (b) show the mean sea level pressure (MSLP) field for the arpoper forecast and the operational 4D-Var ARPEGE analysis on 11 November 2001 at 0000 UTC. The 6-hour accumulated precipitation valid on 10 November 2001 at 1200 UTC for the arpoper forecast 

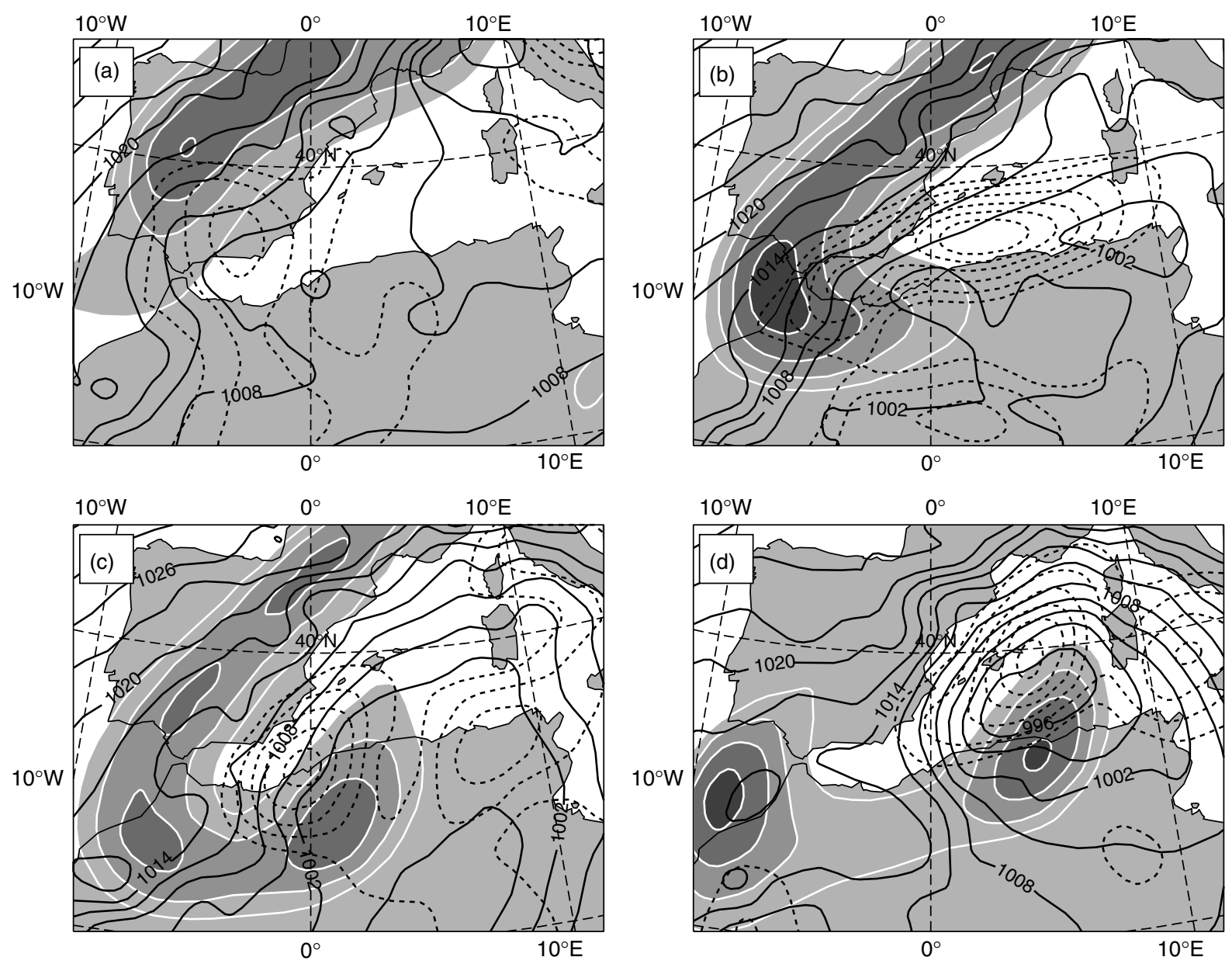

Figure 1. ARPEGE analyses interpolated on a $0.5^{\circ} \times 0.5^{\circ}$ grid on (a) 9 November 2001 at 1200 UTC, (b) 10 November 2001 at 0000 UTC, (c) 10 November 2001 at 1200 UTC and (d) 11 November 2001 at 0000 UTC: $600 \mathrm{hPa}$ ascending vertical velocity (dashed lines, contour interval $2 \mathrm{~Pa} \mathrm{~s}^{-1}$ ), geopotential height of the $1.5 \mathrm{PVU}$ surface (solid white lines with shading, contour interval 200 gpdam, below 800 gpdam) and mean sea level pressure (solid black lines, $\mathrm{hPa}$, contour interval $3 \mathrm{hPa}$ ).

Table I. Characteristics of the ARPEGE experiments, all initialized on 9 November 2001 at 1200 UTC. The locations of A, C and D are indicated on Figure 3.

\begin{tabular}{|c|c|c|}
\hline Experiment & Time/date of PV modifications & Type of modification \\
\hline arpoper & - & - \\
\hline arpmod1 & 1200 UTC; 9 November 2001 & $\begin{array}{l}\text { Displacement by } 1.5^{\circ} \mathrm{W} \text { and } 1.5^{\circ} \mathrm{S} \text { of the } \mathrm{PV} \\
\text { maximum located at } \mathrm{A}\end{array}$ \\
\hline arpmod2 & 1800 UTC; 9 November 2001 & Strengthening of the PV gradient at $\mathrm{C}$ \\
\hline arpmod3 & 0000 UTC; 10 November 2001 & Strengthening of the PV gradient at $\mathrm{D}$ \\
\hline $\operatorname{arpmod} 11$ & 1200 UTC; 9 November 2001 & $\begin{array}{l}\text { As arpmod } 1 \text {, but attenuation of the PV maximum } \\
\text { by } 25 \%\end{array}$ \\
\hline $\operatorname{arpmod} 12$ & 1200 UTC; 9 November 2001 & As arpmod 1 , but displacement by $1.5^{\circ} \mathrm{W}$ and $1^{\circ} \mathrm{S}$ \\
\hline
\end{tabular}

together with the rain-gauge observations are displayed in Figure 2(c).

The arpoper experiment strongly overestimated the intensity of the surface cyclogenesis as it produced, 36 hours ahead, a surface low with a central MSLP value of $984 \mathrm{hPa}$ (Figure 2(b)) as against only $994 \mathrm{hPa}$ for the operational ARPEGE analysis (Figure 2(a)). Also note a $150 \mathrm{~km}$ displacement of the MSLP minimum towards the southwest. In addition to the poor accuracy of the surface pressure forecast, arpoper did not succeed in providing a good precipitation forecast 24 hours ahead (Figure 2(c)). Actually, arpoper captured neither the large amounts of precipitation, exceeding $100 \mathrm{~mm}$ in 6 hours observed over Algiers, nor the area of moderate rainfall over the Algerian/Moroccan border (Figure 2(c)).

\subsection{Forecasts using modified initial PV fields}

In this section, we will examine the impact of applying PV modifications to the precipitation and surface cyclone 

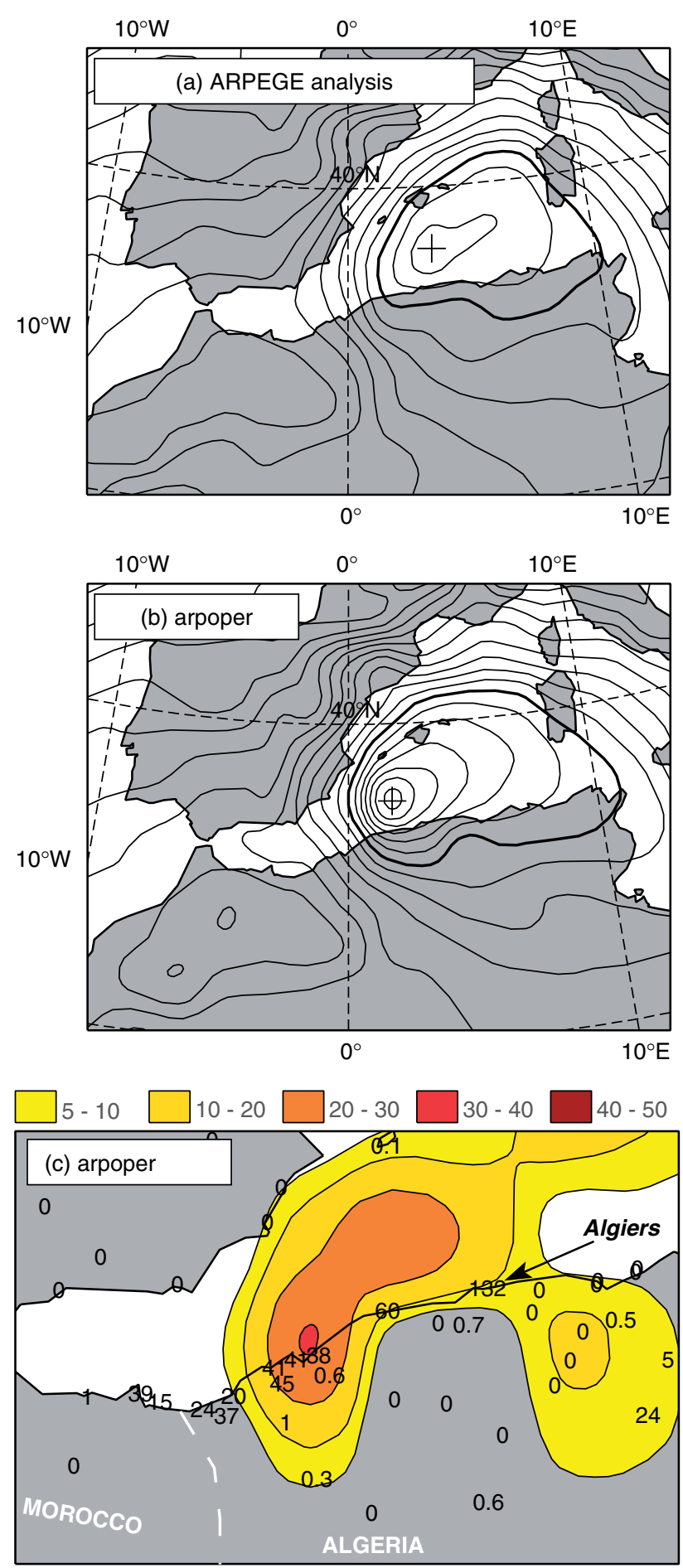

Figure 2. Mean sea level pressure (hPa, contour interval $2.5 \mathrm{hPa}$ ) on 11 November 2001 at 0000 UTC for (a) the operational 4D-Var ARPEGE analysis and (b) the arpoper forecast. (c) shows the 6-hour accumulated rainfall $(\mathrm{mm})$ valid on 10 November at 1200 UTC obtained from the arpoper forecast together with the rain-gauge observations. In (a) and (b), the thick black line indicates the $1000 \mathrm{hPa}$ isobar, and the cross denotes the location of the cyclone's centre. Some geographical details are also shown in (c). This figure is available in colour online at www.interscience.wiley.com/journal/qj forecasts. The PV corrections were applied either at the initial time (i.e. on a 4D-Var operational analysis) or directly within the arpoper forecast (experiments arpmod2 and arpmod3; section 4.2.1 and Table I provide more details). Some characteristics of the experiments using modified PV fields are given in Table I.

\subsubsection{Summary of the PV modifications}

Figure 3 shows a summary of the PV corrections performed. On 9 November 2001 at 1200 UTC, the overall structure of the dry intrusion seems to be well captured by the operational 4D-Var analysis (Figure 3(a)). However, there is no correspondence between the localized maximum of PV and that of brightness temperatures, denoted by $\mathrm{A}$ and $\mathrm{B}$ respectively on Figure 3(a). At this time, which corresponds to the incipient stage of cyclogenesis, the PV maximum should be collocated with the darkest part of the WV image (e.g. Røsting and Kristjánsson, 2008). Therefore, we applied a local modification consisting of moving the area of high PV over the dry slots observed in the WV imagery (Figure 3(d)). The forecast starting from the modified analysis was called arpmodl.

The PV modifications applied directly to the arpoper forecast mainly consisted of strengthening the PV gradient between the dry stratospheric intrusion and the cloud system associated with the surface low. On 9 November 2001 at 1800 UTC and on 10 November 2001 at 0000 UTC, the leading edge of the southeastern part of the upper-level PV field overruns the cloud system materialized by low brightness temperature values $(\mathrm{C}$ on Figure 3(b) and D on Figure 3(c) respectively). At this stage of cyclogenesis development, it is not likely that the dry intrusion mixes with the convective cloud structures. For each time, the PV gradient was strengthened by both reducing PV values in the cloud head and increasing them in the dry intrusion (Figures 3(e) and (f)). The new forecasts starting from the modified arpoper fields at $t+6$ and $t+12$ were called arpmod 2 and arpmod 3 respectively.

\subsubsection{Impact of the modifications on the precipitation and cyclone forecasts}

Figures 4(a)-(c) show the MSLP forecast valid on 11 November 2001 at 0000 UTC for the experiments using modified PV fields. The 6-hour accumulated precipitation valid on 10 November 2001 at 1200 UTC for these experiments together with the rain-gauge observations are displayed in Figure 4(d)-(f). The time evolution of the MSLP at the cyclone's centre and of the mean absolute error (MAE) between the various experiments and the ARPEGE analyses are shown in Figure 5.

Figures 4(a), 4(d) and 5 clearly demonstrate the positive impact of applying PV corrections at the initial time. Actually, the temporal evolution of the developing low simulated in arpmodl is much closer to the ARPEGE analyses than the one simulated by arpoper (Figure 5). Precisely, arpmodl is the sole experiment that correctly captured the MSLP minimum on 11 November 2001 at 0000 UTC. On average, arpmodl gives MAE 

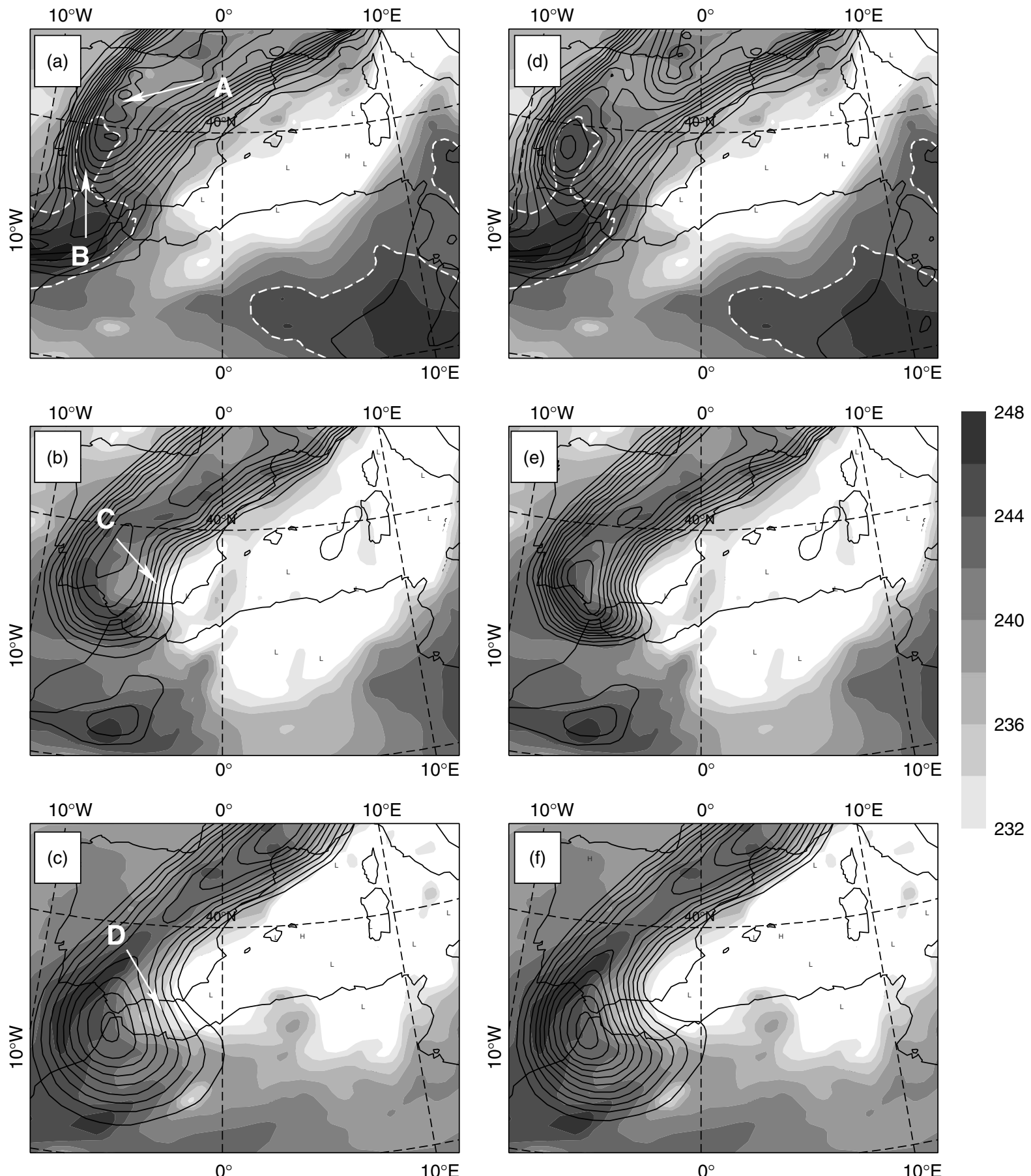

Figure 3. Summary of the potential vorticity modifications for the arpmodl, arpmod 2 and arpmod3 experiments: METEOSAT-7 water vapour brightness temperatures (shading, K) and $300 \mathrm{hPa}$ potential vorticity (solid lines, contour interval $0.5 \mathrm{PVU}$, above 1 PVU) on (a) and (d) 9 November 2001 at 1200 UTC; (b) and (e) 9 November 2001 at 1800 UTC; (c) and (f) 10 November 2001 at 0000 UTC. (a), (b) and (c) show the unmodified potential vorticity field from arpoper, and (d), (e) and (f) display the potential vorticity field resulting from the modifications. The white dashed lines in (a) and (d) indicate the $242 \mathrm{~K}$ contour for the brightness temperature field. The letters A, B, C and D in (a)-(c) indicate the locations where potential vorticity corrections were applied (see text for details).

$50-60 \%$ lower than arpoper. Finally, the gain provided by the initial corrections is associated with a substantial improvement in both the cyclone forecast (Figure 4(a) and Figure 2(a) for the reference) and the precipitation forecast (Figure 4(d)), with a noticeable positive effect on the production of moderate rainfall over Morocco and near Algiers (where no precipitation was simulated in arpoper).
The behaviour of the arpmod 2 and arpmod 3 experiments contrasts with that of arpmodl. The correction corresponding to the arpmod 2 experiment leads to a slight improvement in the cyclogenesis forecast (Figures 5(a) and 5(b)) but has almost no influence on the production of precipitation (Figure4(e)). The location of the cyclone's centre in arpmod2 (Figure 4(b)) is now well forecast as it fits the ARPEGE analyses well (Figure 2(a)) but the low 

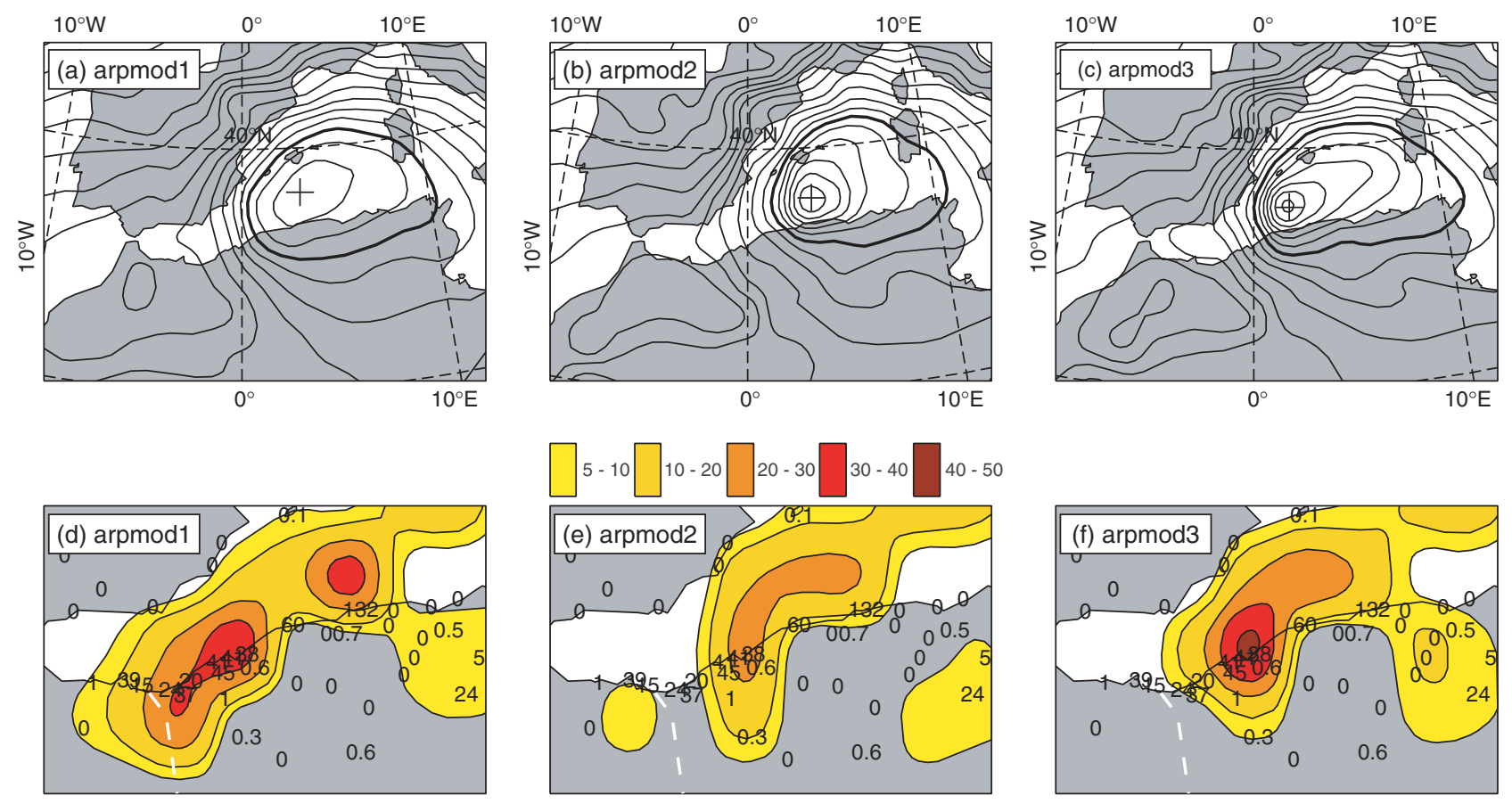

Figure 4. Results for the experiments with modified potential vorticity fields. Mean sea level pressure (hPa, contour interval $2.5 \mathrm{hPa}$ ) on 11 November 2001 at 0000 UTC for (a) arpmodl, (b) arpmod2 and (c) arpmod3, and 6-hour accumulated rainfall (mm) valid on 10 November at 1200 UTC obtained from (d) arpmodl, (e) arpmod2 and (f) arpmod3, together with the rain-gauge observations. In (a)-(c), the thick black line represents the $1000 \mathrm{hPa}$ isobar, and the the cross the location of the cyclone's centre. The dashed white line in (d)-(f) approximately indicates the Algerian/Moroccan border. This figure is available in colour online at www.interscience.wiley.com/journal/qj
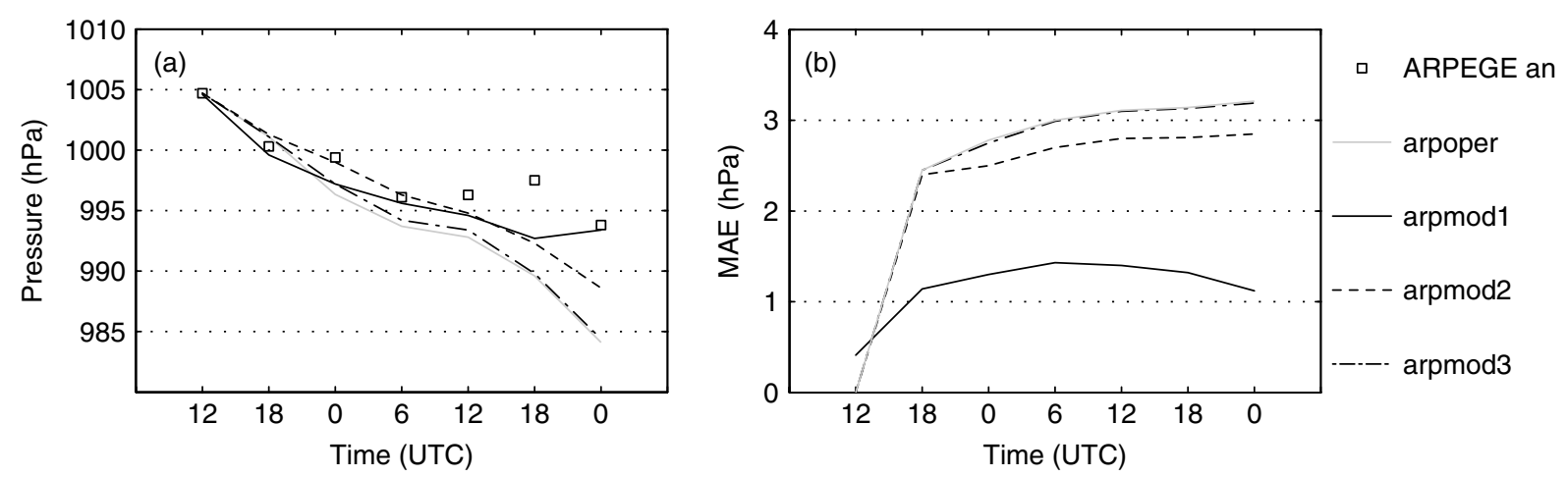

Figure 5. Results for the experiments with modified potential vorticity fields: Time evolution of (a) the mean sea level pressure (MSLP, hPa) at the cyclone centre and (b) the mean absolute error (hPa) between the forecast and analyzed MSLP fields from 9 November 2001 at 1200 UTC to 11 November 2001 at 0000 UTC from 6-hourly values.

is still too deep. In contrast, the PV modifications introduced in arpmod 3 have hardly any effect on the forecast of the surface cyclone (Figures 4(c) and 5). The most noticeable impact of the corrections is an increase in the precipitation maximum at the coast (almost $45 \mathrm{~mm}$ in 6 hours for arpmod 3 against $32 \mathrm{~mm}$ in 6 hours for arpoper).

\subsection{Dynamical analysis}

A dynamical analysis of each experiment was conducted to understand why the modifications we performed either led to an improvement of the forecast skill (arpmodl and, to a lesser extent, arpmod2) or had no effect on it (arpmod3). We will place special emphasis on the mature stage of cyclogenesis (on 11 November 2001 at 0000 UTC).

In recent numerical studies (Arreola et al., 2003; Romero, 2008), it has been shown that both the upperlevel PV anomalies and the diabatically generated lowlevel PV contributed to the deepening of the present cyclone during its mature stage (i.e. on 11 November 2001 at 0000 UTC). In the present study, looking at the impact of the PV correction on the evolution of the upper-level flow showed that the perturbation introduced in each sensitivity experiment propagated towards the east/southeast and induced downstream/upstream effects resulting in a wave-train-like PV perturbation field after 36 hours of simulation (not shown). Although the baroclinic interaction (linked with the presence of upper-level positive $\mathrm{PV}$ anomalies) may largely explain the deepening 
and the overall movement of the surface low, the examination of upper-level PV fields did not provide more insight into the dynamical reasons leading to the improvement (or lack thereof) in the surface cyclone forecast.

Following previous findings concerning the life cycle of extratropical cyclones (e.g. Mallet et al., 1999), the study of the diabatic component of the PV field was addressed by looking at the low-level PV forecasts. Figure 6 shows the 900-700 hPa layer PV for each experiment and the 3-hour convective precipitation forecast valid on 11 November 2001 at 0000 UTC. The location and amplitude of the low-level PV maxima fits that of the cyclone centre well for each experiment. For example, arpoper modelled PV values of about 2.1 PVU and a central pressure of $984 \mathrm{hPa}$, as against $1 \mathrm{PVU}$ and $994 \mathrm{hPa}$ for arpmodl (note that two maxima are modelled in arpmodl but the cyclonic core is mainly associated with the one close to Mallorca). In agreement with the surface pressure forecast, arpmod2 produced large PV values east of the arpoper maximum whereas arpmod3 hardly differed from arpoper. The strong correlation between the position of precipitating areas and high low-level PV values indicated that these maxima were mainly due to the release of latent heat associated with deep convection. Therefore, at the mature stage of cyclogenesis, it appears
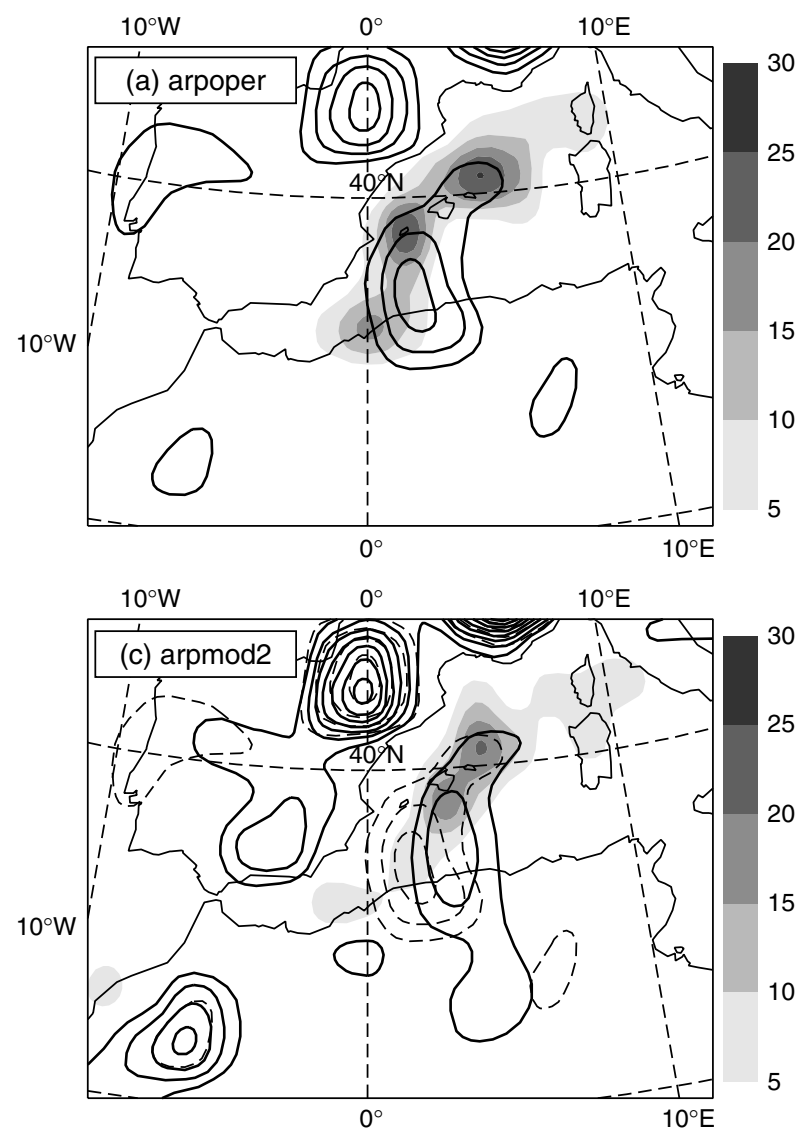

that an accurate forecast of both the position and the deepening of the surface low was strongly dependent on the intensity and the location of deep convection (and the associated precipitation) in each experiment.

\section{Meso-NH experiments}

Although the arpmodl experiment succeeded reasonably well in forecasting the time evolution of the surface cyclogenesis, none of the ARPEGE experiments were able to produce large rainfall amounts near Algiers, a result probably related to the poor resolution of orographically induced processes when ARPEGE is used at such a horizontal grid mesh. In this section, we will study the impact of applying PV modifications at initial time using cloud-resolving numerical simulations performed with the non-hydrostatic Meso-NH model. For this purpose, we performed two simulations starting from and coupled with either the arpoper experiment or the best ARPEGE forecast, namely arpmod1. These are called mnhoper and mnhmod1, respectively.

\subsection{Design of the experiments}

The Meso-NH numerical simulations were performed on two nested grids. The coarser domain had $300 \times 200$
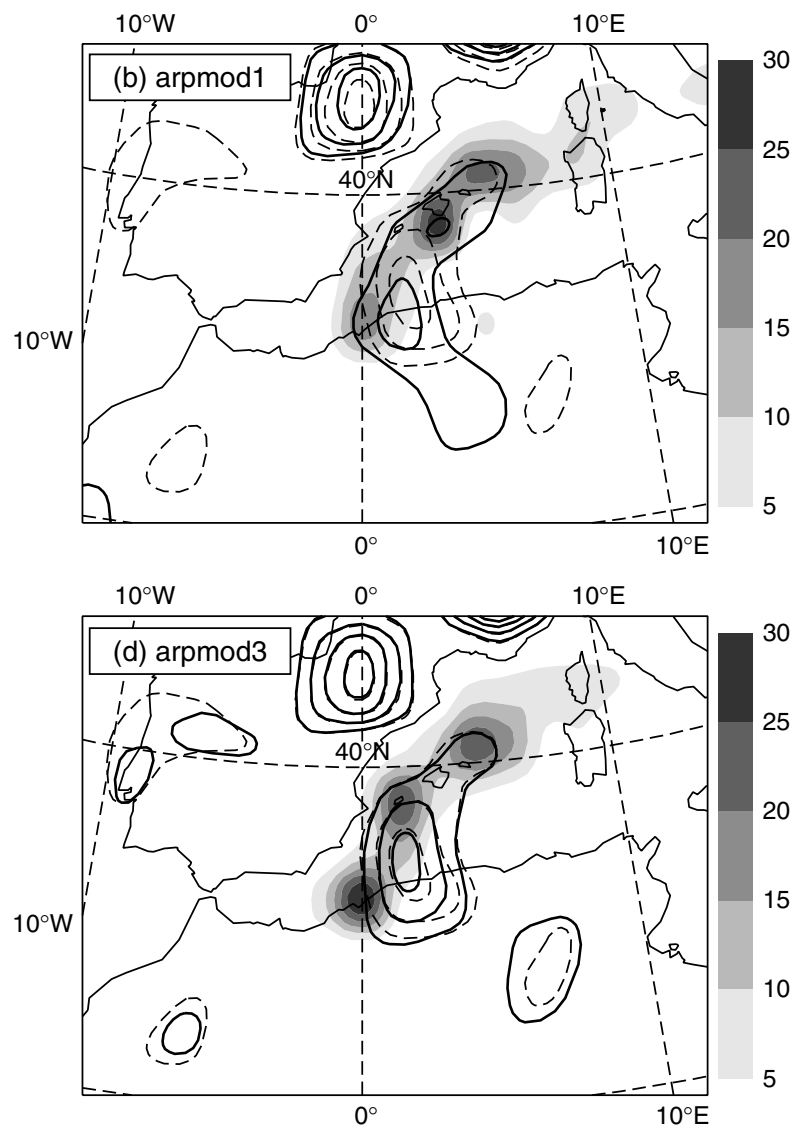

Figure 6. Results for the ARPEGE experiments on 11 November 2001 at 0000 UTC: Vertically integrated (900-700 hPa) potential vorticity (thick black lines, PVU, contour interval 0.5 PVU, above 1 PVU) and 3-hour accumulated convective precipitation (shading, mm) for (a) arpoper, (b) arpmod1, (c) arpmod2 and (d) arpmod3. In (b)-(d), the 900-700 hPa layer potential vorticity for arpoper is also shown in thin dashed lines (PVU, contour interval 0.5 PVU, above 1 PVU). 
grid points and a horizontal grid spacing of $10 \mathrm{~km}$, and the finer $250 \times 180$ grid points and a $2 \mathrm{~km}$ mesh. The vertical grid had 52 levels up to $21 \mathrm{~km}$ with a level spacing of $60 \mathrm{~m}$ near the ground and $600 \mathrm{~m}$ at high altitude. The microphysical scheme included the three water phases with five species of precipitating and nonprecipitating liquid and solid water (Pinty and Jabouille, 1998). The turbulence parametrization was based on a 1.5-order closure (Cuxart et al., 2000). For the coarser grid, the mixing length followed the method of Bougeault and Lacarrère (1989) and the turbulent fluxes were purely vertical whereas three-dimensional turbulent fluxes were modelled for the innermost domain. The mass-flux convection scheme of Kain and Fritsch (1993) adapted to the Meso-NH model by Bechtold et al. (2001) was activated for the coarser grid. For the inner grid, convection was assumed to be explicitly resolved and the convection scheme was switched off. The domains of simulation are depicted on Figure 7. To assess the realism of the cloud forecast in the experiments, synthetic brightness temperatures corresponding to the METEOSAT-7 infrared observations were computed offline using the Radiative Transfer for Tiros Operational Vertical Sounder (RTTOV) code version 8.7 (Saunders et al., 2005) and compared with observations following Chaboureau et al. (2000).

\subsection{Impact of the PV modifications on the $10 \mathrm{~km}$ model runs}

In this section, we examine the behaviour of the $10 \mathrm{~km}$ simulations that provided the lateral boundary conditions to the $2 \mathrm{~km}$ model runs. We assessed the ability of the $10 \mathrm{~km}$ model runs to forecast the main features of the event under study: the cyclone of 11 November 2001 at 0000 UTC, the 6-hour accumulated precipitation valid on 10 November at 1200 UTC and the cloud cover, which provides essential information about the convective activity.

\subsubsection{Cyclone and precipitation forecasts}

Figure 8 shows the MSLP forecast valid on 11 November 2001 at 0000 UTC for each experiment. The MSLP

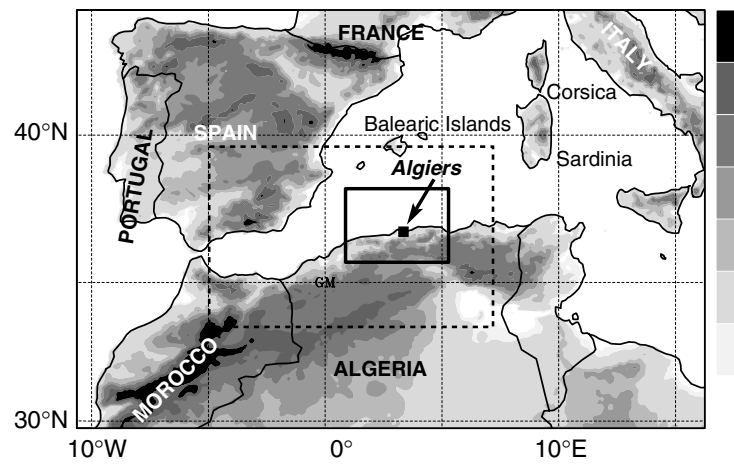

1600.

1200.

800.0

600.0

400.0

100.0

50.00

Figure 7. Topography $(\mathrm{m})$ of the $10 \mathrm{~km}$ mesh size domain used of the numerical experiments performed with Meso-NH. The solid black box indicates the location of the nested model with $2 \mathrm{~km}$ horizontal resolution. The dashed black box denotes the domain $\mathcal{D}$ used for statistical calculations. field from the operational 4D-Var ARPEGE analysis valid on 11 November 2001 at 0000 UTC shown on Figure 8(a) appears less smoothed than the one shown on Figure 2(a), as it was downscaled to the $10 \mathrm{~km}$ grid of Meso-NH. This downscaling process also led to small differences in MSLP at the cyclone centre when interpolating the ARPEGE analyses to the $10 \mathrm{~km}$ Meso$\mathrm{NH}$ grid (Figures 5(a) and 9). The time evolution of the MSLP at the cyclone's centre is shown in Figure 9. While mnhoper showed significant error both in the location and the deepening of the surface cyclone, mnhmodl performed quite well in simulating the cyclone structure as well as the MSLP at its centre. Therefore, like the ARPEGE experiments, the modification introduced at initial time led to an improvement in the cyclone forecast. Moreover, mnhoper performed better than arpoper as it exhibited a smaller error in MSLP at the cyclone's centre (about $4 \mathrm{hPa}$ for mnhoper against $10 \mathrm{hPa}$ for arpoper).

Figure 10 shows the 6-hour accumulated precipitation valid on 10 November 2001 at 1200 UTC for the two experiments at $10 \mathrm{~km}$ grid spacing together with the rain-gauge observations. Apparently, the improvement of the cyclone forecast is associated with a large reorganization of the main precipitating structure (Figure 10(c) displays the difference between the two simulated precipitation fields). Neither of the simulations was able to precisely reproduce the large rainfall amounts observed over Algiers city. Nevertheless, some improvements of the precipitation forecast may be seen in mnhmodl:

- The main precipitating structure has been displaced towards the south and is closer to the Algerian coast.

- mnhmodl produced more intense precipitation (between 50 and $110 \mathrm{~mm}$ in 6 hours) in better accordance with the maximum observed values.

- The precipitation pattern extends over northeast Morocco and fits the observations over land better.

Quantitative assessments based on the comparisons between the $10 \mathrm{~km}$ model runs and the observations for the same accumulation period are shown in Figure 11. The set of statistical scores we used was composed of the correlation coefficient, the root mean square error (RMSE) and the Heidke Skill score (HSS) computed for four thresholds $(0.1,1,5$ and $10 \mathrm{~mm}$ in 6 hours) to measure the ability of the simulations to forecast light to heavy rainfall. The scores were computed for the domain $\mathcal{D}$ (Figure 7). Obviously, the correction introduced at initial time led both to an improvement of the overall precipitation forecast (lower RMSE and higher correlation for mnhmodl than mnhoper) and to a better ability in forecasting moderate to heavy rainfall (higher HSS for mnhmodl than mnhoper).

\subsubsection{Cloud cover forecast}

The so-called model-to-satellite approach is an efficient tool for verification of mesoscale forecasts. Here, we used METEOSAT-7 infrared brightness temperatures in 


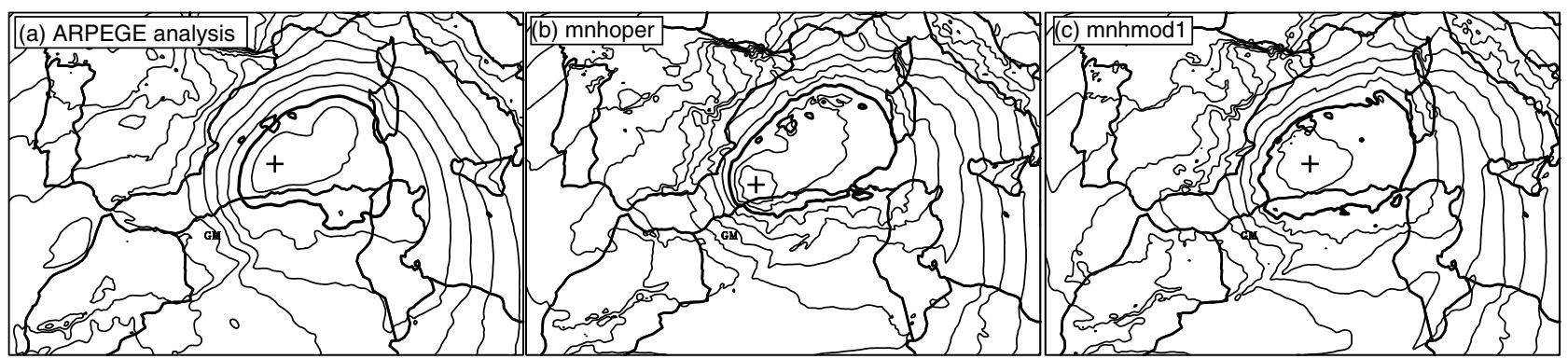

Figure 8. Results for the $10 \mathrm{~km}$ model runs valid on 11 November 2001 at 0000 UTC: Mean sea level pressure (hPa, contour interval $2.5 \mathrm{hPa}$ ) for (a) the operational 4D-Var ARPEGE analysis, (b) mnhoper and (c) mnhmodl. The thick black line in each panel indicates the $1000 \mathrm{hPa}$ isobar and the black cross denotes the location of the cyclone's centre.

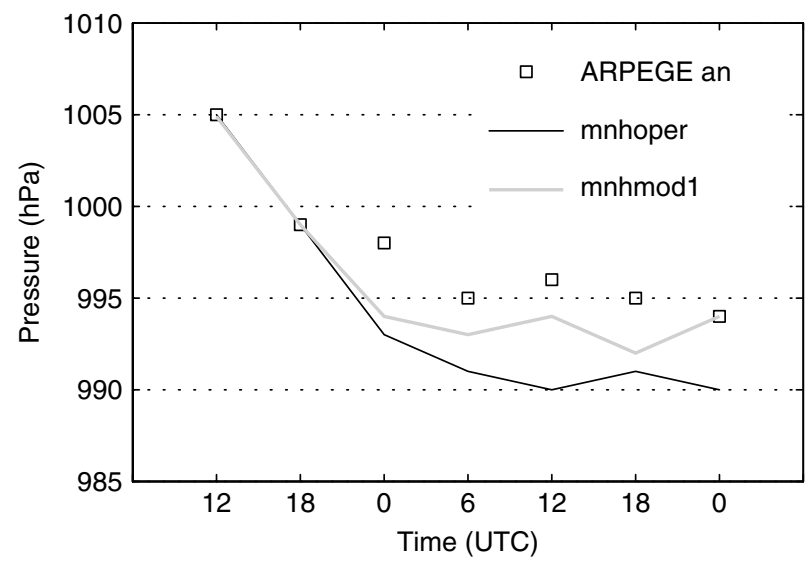

Figure 9. Results for the $10 \mathrm{~km}$ model runs: Time evolution of the mean sea level pressure $(\mathrm{hPa})$ at the cyclone centre from 9 November 2001 at 1200 UTC to 11 November 2001 at 0000 UTC from 6-hourly values.

the $10.5-12 \mu \mathrm{m}$ bandwidth as it is mainly affected by cloud-top heights. The comparison between observed and synthetic brightness temperatures was achieved using conventional scores, the root mean square error and the equitable threat score (RMSE-SAT and ETS-SAT, respectively). For computation of the ETS-SAT, we used a threshold of $250 \mathrm{~K}\left(-23^{\circ} \mathrm{C}\right)$ to focus on deep high clouds only. The temporal evolution of these scores computed over $\mathcal{D}$ is shown in Figure 12. The periods of strong convective activity are also reported in Figure 12.

First, we note that both experiments were very successful at reproducing the cloud cover between the two periods of strong convection. Although the time evolution of both the RMSE-SAT and the ETS-SAT of mnhmod1 followed approximately that of mnhoper, the initial PV corrections led to a constant positive impact after 9 November at 2000 UTC. The reduction of the error is still noticeable on 10 November until 0600 UTC, i.e. during the period preceding the peak of simulated precipitation.

\subsection{Impact of the PV modifications on the $2 \mathrm{~km}$ model runs}

The 6-hour accumulated rain forecasts are now shown for the $2 \mathrm{~km}$ model runs (Figure 13). Like the $10 \mathrm{~km}$ precipitation forecast (Figure 10), mnhmodl produced a precipitation pattern that was close to the Algerian coast while mnhoper did not. The mnhmodl experiment even
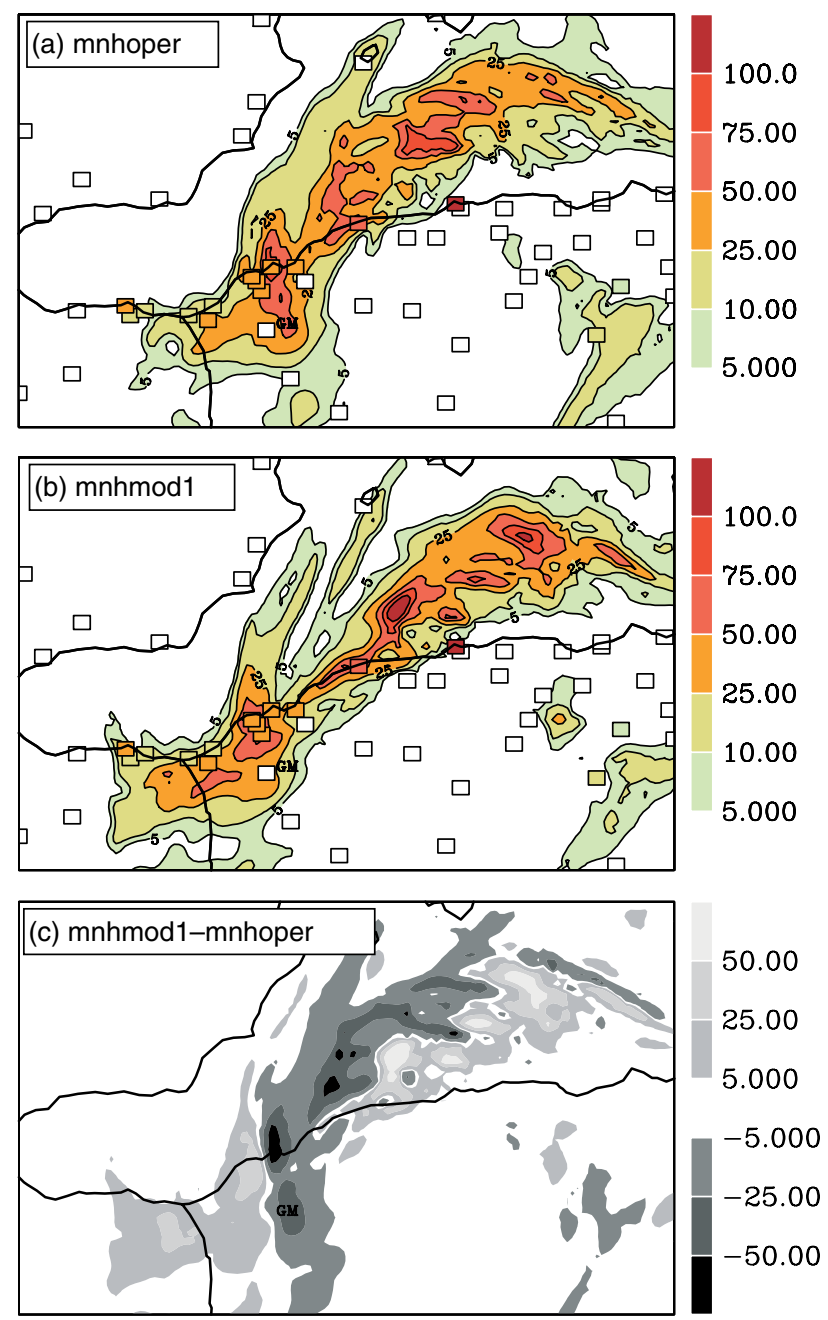

Figure 10. Results for the $10 \mathrm{~km}$ model runs: 6-hour accumulated rainfall $(\mathrm{mm})$ valid on 10 November 2001 at 1200 UTC obtained from (a) mnhoper and (b) mnhmodl; (c) is the difference (b) minus (a). The locations of rain-gauge observations are indicated by the square boxes on (a) and (b). This figure is available in colour online at www.interscience.wiley.com/journal/qj

modelled moderate rainfall over the relief surrounding Algiers (almost $40 \mathrm{~mm}$ in 6 hours) and heavy rain cores over the sea (more than $100 \mathrm{~mm}$ in 6 hours) in contrast with mnhoper which only simulated moderate precipitation off Algiers. 

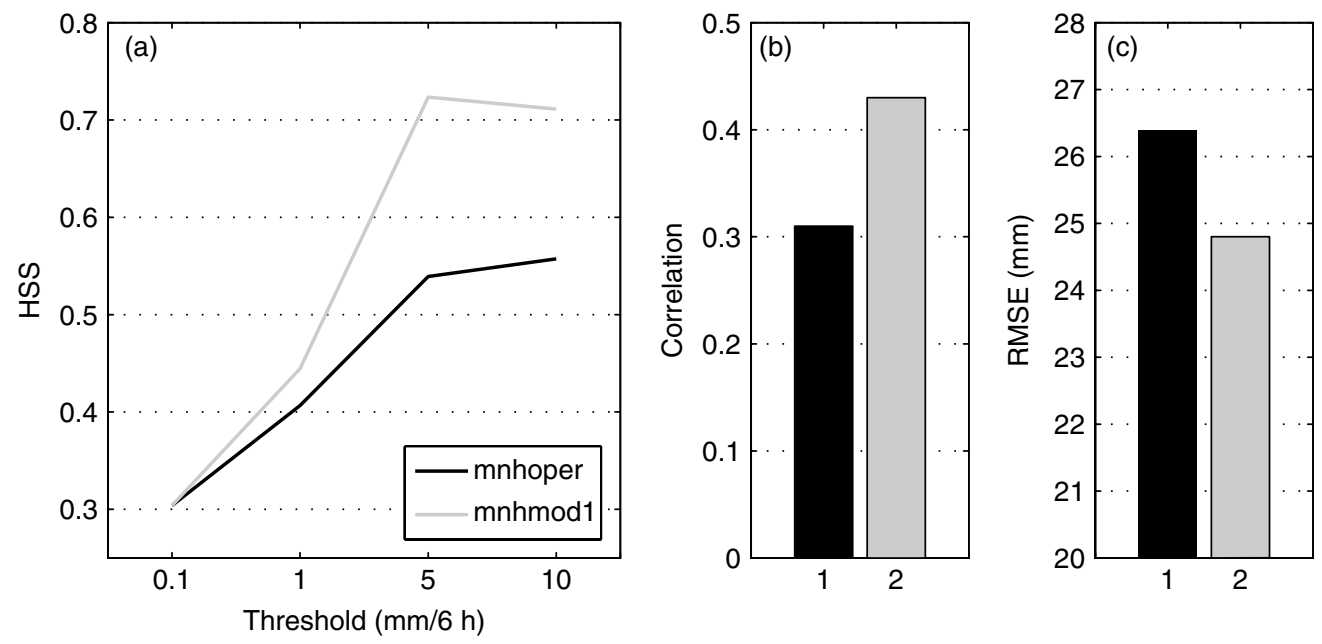

Figure 11. Statistics derived from comparisons between the $10 \mathrm{~km}$ model runs and the rain-gauge measurements: (a) Heidke skill score, (b) correlation coefficient and (c) root mean square error. In (b) and (c), the numbers 1 and 2 on the $x$-axis refer to the experiments mnhoper and mnhmodl, respectively. The scores were computed over domain $\mathcal{D}$ for the 6-hour accumulated rainfall from $10 \mathrm{November} 2001$ at $0600 \mathrm{UTC}$. A total of 54 observations were used and the model results were interpolated at the rain-gauge locations.
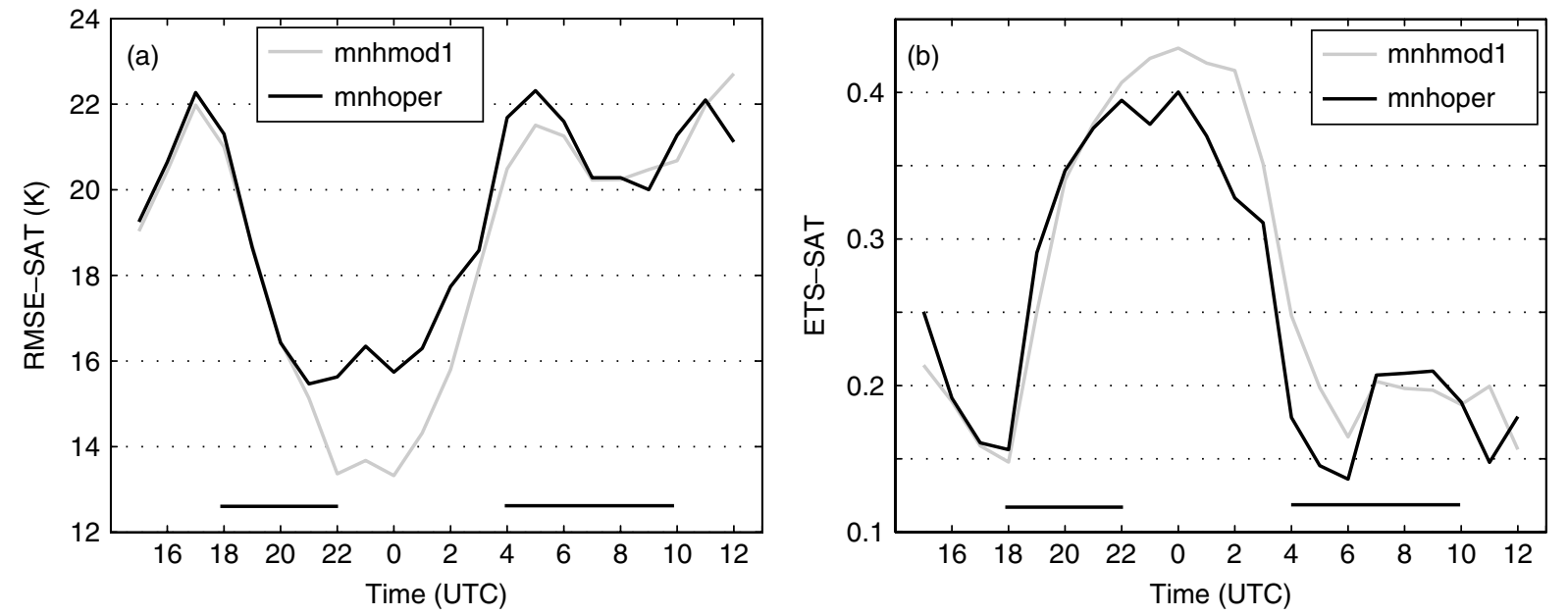

Figure 12. Results for the $10 \mathrm{~km}$ model runs: time evolution of the root mean square difference of the brightness temperatures (K) between the Meso-NH experiments and the METEOSAT-7 infrared observations averaged over domain $\mathcal{D}$ from 9 November 2001 at 1500 UTC to 10 November 2001 at 1200 UTC from hourly values; (b) is as (a) but for the equitable threat score. The periods of strong convective activity are indicated by horizontal black lines.

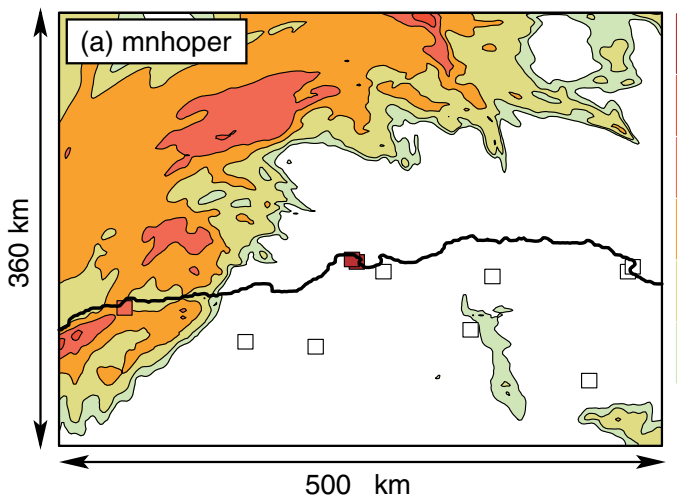

100.0

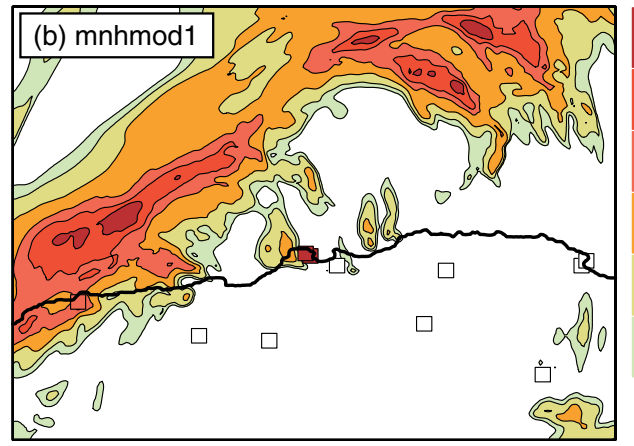

100.0

75.00

50.00

25.00

10.00

10.00

5.000

(2) 0

5.000

Figure 13. As Figure 10(a) and (b), but for the $2 \mathrm{~km}$ model runs. This figure is available in colour online at www.interscience.wiley.com/journal/qj 

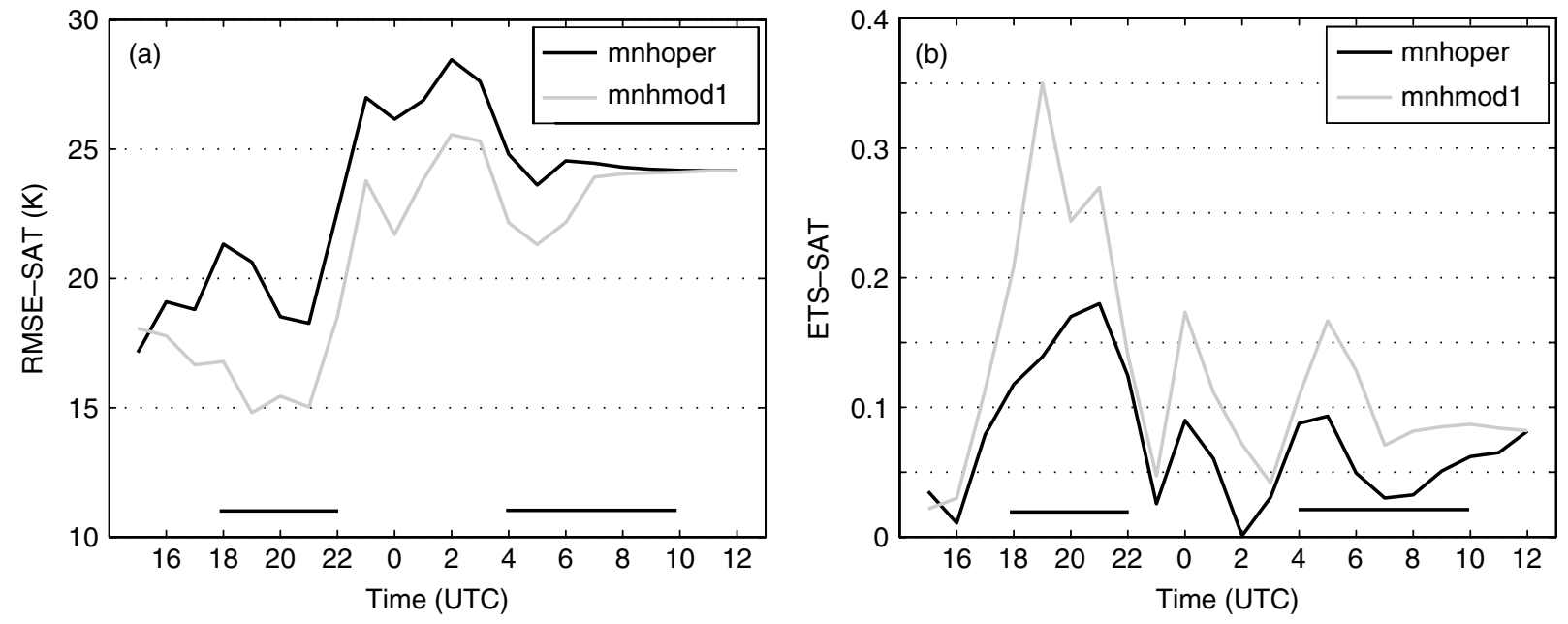

Figure 14. Results for the $2 \mathrm{~km}$ model runs: time evolution of the root mean square difference of the brightness temperatures (K) between the Meso-NH experiments and the METEOSAT-7 infrared observations averaged over the $2 \mathrm{~km}$ domain from 9 November 2001 at 1500 UTC to 10 November 2001 at 1200 UTC from hourly values; (b) is as (a), but for the equitable threat score. The periods of strong convective activity are indicated by horizontal black lines.

The sparsity of rain-gauges did not allow the quantitative evaluation of the precipitation forecasts at $2 \mathrm{~km}$ grid spacing. To overcome this limitation, we performed statistical comparisons of the simulated brightness temperatures derived from the $2 \mathrm{~km}$ model runs and METEOSAT7 infrared observations. As the METEOSAT-7 observations have a horizontal resolution of approximately $8 \mathrm{~km}$ in midlatitudes, we performed the comparisons by interpolating the model results and the satellite observations on a grid of $10 \mathrm{~km}$ spacing covering the innermost domain of simulation. The results in terms of RMSESAT and ETS-SAT (with a threshold of $250 \mathrm{~K}$ ) averaged over the entire $2 \mathrm{~km}$ domain are shown in Figure 14.

Both simulations displayed a comparable temporal evolution of the RMSE-SAT, but the initial PV correction introduced in mnhmodl led to a substantial reduction of the error during the two periods of heavy convection (Figure 14(a)). Actually, the mnhmodl RMSE-SAT was $20-30 \%$ (10\%) lower than that of mnhoper during the first (second) period of strong convective activity. This tends to demonstrate that mnhmodl is better able to reproduce the observed cloudiness than mnhoper is. The results provided by the computation of the ETS-SAT (Figure 14(b)) reinforced this conclusion, as mnhmodl performed better in modelling the deep clouds that characterized this convective event.

\section{Robustness of the PV modification approach}

Without wishing to detract from the merit of the present approach since the forecast improvement is large, we should, nevertheless, stress the subjective nature of the method. The magnitudes of the corrections are tuned using METEOSAT-7 WV pictures even though there is no direct relationship between PV and water vapour and the shape of the corrections strongly depends on some parameters of the PV inversion methods. We therefore addressed the robustness of the present approach by performing two alternative modifications of the initial analysis of 9 November 2001 at 1200 UTC by changing the parameters (amplitude and location) of the chosen PV modifications. These two experiments, designed to improve the initial condition in the same way as arpmodl, were called arpmod 11 and arpmod 12 and may be viewed as variations of the arpmodl experiment: arpmodll was a displacement similar to arpmodl, but the amplitude of the PV pattern which was shifted over the dry slot was attenuated by $25 \%$; arpmod 12 was a correction similar to arpmodl but the PV pattern was displaced to the south by $0.5^{\circ}$ less. Figure 15 shows the MSLP and the height of the 1.5 PVU surface forecasts for each alternative experiment as well as the MSLP differences between the alternative forecasts and arpmodl valid on 11 November 2001 at 0000 UTC

Apparently, the initial PV differences between the alternative forecasts and arpmodl led to significant changes of the evolution of the upper-level flow: arpmod11 produced a deeper trough (characterized by lower values of the height of the 1.5 PVU surface) than arpmodl, which could partly explain the greater deepening of the surface low for this alternative experiment (Figure 15(a)). The cyclonic curvature of the tropopause anomaly of arpmod12 is much more pronounced than that of arpmodl (Figure 15(b)), suggesting a rapid progression of the surface cyclone towards the west. After 36 hours of simulation, the cyclonic development produced by arpmodl1 had become quite strong and was located to the east of the arpmodl low (Figure 15(c)), suggesting that the weakening of the initial PV anomaly was detrimental to correct forecasting of the minimum location. In the arpmod 12 case, the cyclone forecast on 11 November 2001 at 0000 UTC looked like that of arpoper, with somewhat larger values of the MSLP at the centre of the cyclone (Figure 15(d)). 

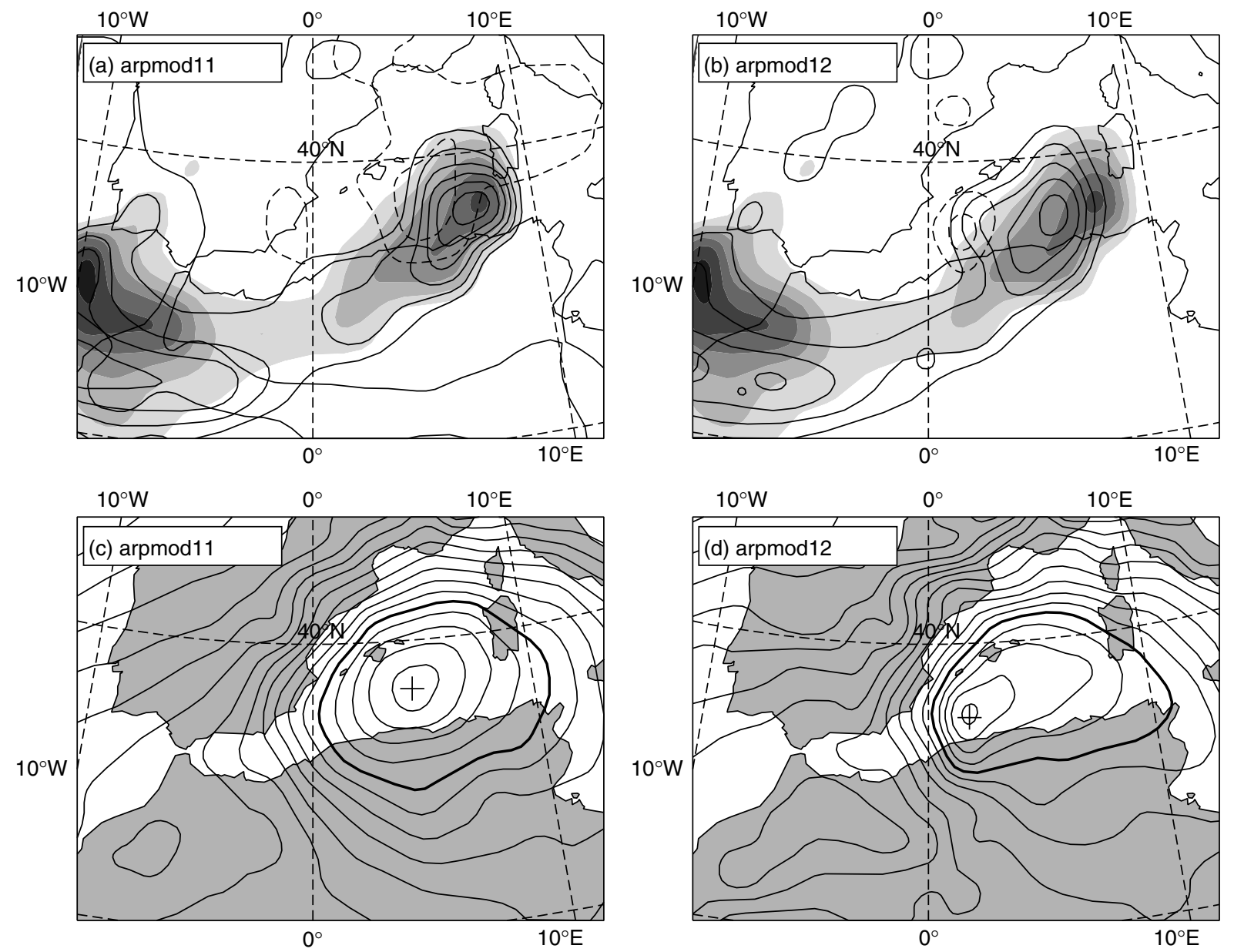

Figure 15. Results for the alternative modification experiments on 11 November 2001 at 0000 UTC. Geopotential height of the 1.5 PVU surface (thick solid lines, contour interval of 200 gpdam, below 800 gpdam) and difference from arpmodl of the mean sea level pressure (thin black lines, $\mathrm{hPa}$, contour interval $2 \mathrm{hPa}$; dashed contours show negative values and zero contours are omitted) for (a) arpmod11 and (b) arpmod12. Mean sea level pressure ( $\mathrm{hPa}$, contour interval $2.5 \mathrm{hPa}$ ) for (c) arpmod11, (d) arpmod12. The geopotential height of the $1.5 \mathrm{PVU}$ surface (shading, contour interval of 200 gpdam below 800 gpdam) for arpmodl is also shown in (a) and (b). In (c) and (d) the thick black line indicates the $1000 \mathrm{hPa}$ isobar, and the black cross the location of the cyclone's centre.

Bearing in mind the fact that the variations of the parameters of the PV modifications were determined with the intention of modifying the initial condition in the same way, the large differences displayed between the three experiments, arpmod1, arpmod11 and arpmod12, suggest that the present approach should be applied with care. Furthermore, it is shown that a combination of initial corrections of both the location and the amplitude of the PV maximum is crucial for the success of arpmodl in forecasting the surface pressure development with accuracy. These results are in good agreement with the previous work of Swarbrick (2001) who pointed out the difficulty in implementing PV corrections procedures for operational use.

\section{Summary and further discussion}

In this study, the influence of local PV modifications on numerical simulations of a deep Mediterranean cyclone has been investigated. This storm dramatically affected northern Algeria and the Balearic Islands and, although it was reasonably well forecast by operational meteorological centres, some uncertainties about its strength and its associated precipitation remained even at very short range. Using the French operational numerical weather prediction model ARPEGE, we showed that the forecast starting from the operational analysis of 9 November at 1200 UTC was not able to accurately reproduce the development of the surface depression. It appears that local corrections of the upper-level PV field (or of the topography of the dynamical tropopause) guided by METEOSAT-7 WV observations may lead to a substantial improvement of the forecast in terms of surface pressure and accumulated precipitation.

The use of such a low-resolution model did not seem to be optimal for this case-study as most of the convective ascents (and the subsequent precipitation) were probably triggered by the North African orography. As the simulated precipitation amounts were too weak even for the most successful ARPEGE experiment, we then performed two simulations at very high horizontal resolution with the Meso-NH model using the worst and 
the best ARPEGE run as boundary conditions. The Meso$\mathrm{NH}$ experiments were better than the ARPEGE ones in the sense that they were able to simulate more realistic (or larger) amounts of rainfall. Qualitative and quantitative assessments of these simulations against rain-gauge and satellite observations indicated that the impact of initial PV corrections was positive, especially during the periods of strong convective activity and thus for the precipitation forecast.

Finally, two alternative ARPEGE experiments were performed to study the sensitivity of the forecast to the type of modifications applied. PV corrections differing slightly from those of the most successful experiments were introduced at initial time and their impact on the cyclone forecast was studied. Such small variations of the initial corrections led to strong differences between the experiments. While one of the simulations gave results close to the best ARPEGE experiment, the second completely failed to provide an accurate representation of the depression at its mature stage. This proves that this Mediterranean cyclone was very sensitive to slight perturbations of the upper-level flow, like several other cases of cyclogenesis (Huo et al., 1999; Romero, 2001; Lambert et al., 2004, among others).

From these previous works, it was also shown that initial PV modifications may be useful in the framework of the generation of short-term ensemble forecasting as the initial PV perturbations (if they were applied in sensitive regions) would grow rapidly, leading to huge differences between two numerical forecasts taking slightly different initial conditions. By using a nonlinear quasigeostrophic model, Plu and Arbogast (2005) investigated the use of PV perturbations for the generation of shortterm ensembles for an idealized baroclinic cyclogenesis initially defined by two anomalies, one at the tropopause and the other near the ground. They showed that an ensemble based on perturbations of the upper-level precursor (both in amplitude and in position) was more able than singular vector ensembles to reproduce the statistical distribution of each of the possible evolutions of the cyclogenesis. Following these ideas, and the results of the present paper suggesting that upper-level dynamics do partly control deep convection and more widespread atmospheric features where moist processes are crucial, ensemble prediction systems dedicated to the mesoscale should at least include initial perturbations that follow upper-level coherent structures.

\section{Acknowledgements}

The authors thank the two reviewers for their helpful comments. This study was supported by the ACI/FNS (Action Coordonnée Incitative/Fonds National de la Science) Aléas et Changements Globaux programme. Computational resources were provided by IDRIS (under project 080569-CP1). METEOSAT-7 observations were obtained from SATMOS and rain-gauge data were provided by Météo-France.

\section{References}

Arbogast P, Maynard K, Crepin F. 2008. Ertel potential vorticity inversion using a digital filter initialization method. $Q$. J. $R$. Meteorol. Soc. 134: 1287-1296.

Argence S, Lambert D, Richard E, Chaboureau JP, Söhne N. 2008. Impact of initial condition uncertainties on the predictability of heavy rainfall in the Mediterranean: A case-study. Q. J. R. Meteorol. Soc. 134: $1775-1788$

Arreola J, Homar V, Romero R, Ramis C, Alonso S. 2003. 'Multiscale numerical study of the 10-12 November 2001 strong cyclogenesis event in the Western Mediterranean'. PLC04-A-00017 in Proceedings of Fourth Plinius Conference on Mediterranean Storms, Mallorca, 2-4 October 2002. European Geophysical Society: Katlenburg-Lindau, Germany.

Baleste MC, Brunet H, Mougel A, Coiffier J, Bourdette N, Bessemoulin P. 2001. Les Tempêtes Exceptionnelles de Noël 1999. Collection Phénomènes Remarquables 7: Météo-France: Toulouse.

Bechtold P, Bazile E, Guichard F, Mascart P, Richard E. 2001. A mass-flux convection scheme for regional and global models. $Q$. $J$. R. Meteorol. Soc. 127: 869-886.

Bougeault P, Lacarrère P. 1989. Parameterization of orography-induced turbulence in a meso-beta scale model. Mon. Weather Rev. 117: $1870-1888$.

Chaboureau JP, Cammas JP, Mascart P, Pinty JP, Claud C, Roca R, Morcrette JJ. 2000. Evaluation of a cloud system life cycle simulated by Meso-NH during FASTEX using METEOSAT radiances and TOVS-3I cloud retrievals. Q. J. R. Meteorol. Soc. 126: 1735-1750.

Chaboureau JP, Claud C. 2006. Satellite-based climatology of Mediterranean cloud systems and their association with large-scale circulation. J. Geophys. Res. 111: D01102, doi:10.1029/2005JD006460.

Courtier P, Freydier C, Geleyn JF, Rabier F, Rochas M. 1991. 'The ARPEGE project at Météo-France'. Proceedings of Seminar on Numerical Methods in Atmospheric Models, Vol. II, 9-13 September 1991. ECMWF: Reading, UK. pp 193-231.

Cuxart J, Bougeault P, Redelsperger, JP. 2000. A turbulence scheme allowing for mesoscale large-eddy simulations. Q. J. R. Meteorol Soc. 127: 869-886.

Demirtas M, Thorpe AJ. 1999. Sensitivity of short-range weather forecasts to local potential vorticity modifications. Mon. Weather Rev. 127: 922-939.

Funatsu BM, Claud C, Chaboureau JP. 2008. A 6-year AMSUbased climatology of upper-level troughs and associated precipitation distribution in the Mediterranean region. J. Geophys. Res. 113: D15120, doi:10.1029/2008JD009918.

Georgiev CG. 1999. Quantitative relationship between METEOSAT WV data and positive potential vorticity anomalies: A case-study over the Mediterranean. Meteorol. Appl. 6: 97-109.

Georgiev CG, Martín F. 2001. Use of potential vorticity fields, METEOSAT water vapour imagery and pseudo water vapour images for evaluating numerical model behaviour. Meteorol. Appl. 8: 57-69.

Guerin R, Desroziers G, Arbogast P. 2006. 4D-Var analysis of potential vorticity pseudo-observations. Q. J. R. Meteorol. Soc. 132: 1283-1298.

Hello G, Arbogast P. 2004. Two different methods to correct the initial conditions applied to the storm of 27 December 1999 over southern France. Meteorol. Appl. 11: 51-57.

Hoskins BJ, McIntyre ME, Robertson AW. 1985. On the use and significance of isentropic potential vorticity maps. Q. J.R. Meteorol. Soc. 111: 877-947.

Huo Z, Zhang DL, Gyakum J. 1999. Interaction of potential vorticity anomalies in extratropical cyclogenesis. Part II: Sensitivity to initial perturbations. Mon. Weather Rev. 127: 2563-2575.

Kain JS, Fritsch JM. 1993. Convective parameterization for mesoscale models: The Kain-Fritsch scheme. In The representation of cumulus convection in numerical models. Emanuel KA, Raymond DJ. (eds.) Meteorol. Monograph 46: 165-170.

Lagouvardos K, Kotroni V. 2000. Use of METEOSAT water-vapour images for the diagnosis of a vigorous stratospheric intrusion over the central Mediterranean. Meteorol. Appl. 7: 205-210.

Lafore JP, Stein J, Asencio N, Bougeault P, Ducrocq V, Duron J, Fisher C, Héreil P, Mascart P, Masson V, Pinty JP, Redelsperger JL, Richard E, Vilà-Guerau de Arellano J. 1998. The Meso-NH atmospheric simulation system. Part I: Adiabatic formulation and control simulations. Ann. Geophys. 16: 90-109.

Lambert D, Arbogast P, Cammas JP, Donnadille J, Mascart P. 2004. A cold-air cyclogenesis study using a potential vorticity inversion method. Q. J. R. Meteorol. Soc. 130: 2953-2970. 
Mallet I, Cammas JP, Mascart P, Bechtold P. 1999. Effects of cloud diabatic heating on the early development of the FASTEX IOP-17 cyclone. Q. J. R. Meteorol. Soc. 125: 3439-3467.

Manders AMM, Verkley WTM, Diepeveen JJ, Moene AR. 2007. Application of a potential vorticity inversion method to a case of rapid cyclogenesis over the Atlantic Ocean. Q. J. R. Meteorol. Soc. 133: $1755-1770$

Mansfield D. 1996. The use of potential vorticity as an operational forecasting tool. Meteorol. Appl. 3: 195-210.

Pinty JP, Jabouille P. 1998. 'A mixed-phase cloud parametrization for use in mesoscale non-hydrostatic models: Simulations of a squallline and of orographic precipitation'. In Proceedings of conference on cloud physics, August 1999, Everett, WA, USA. Amer. Meteorol. Soc: Boston, USA, pp 217-220.

Plu M, Arbogast P. 2005. A cyclogenesis evolving into two distinct scenarios and its implication for short-term ensemble forecasting. Mon. Weather Rev. 133: 2016-2029.

Romero R. 2001. Sensitivity of a heavy rain producing Western Mediterranean cyclone to embedded potential vorticity anomalies. O. J. R. Meteorol. Soc. 127: 2559-2597.

Romero R. 2008. A method for quantifying the impacts and interactions of potential-vorticity anomalies in extratropical cyclones. Q. J.R. Meteorol. Soc. 134: 385-402.
Røsting B, Kristjánsson JE. 2006. Improving simulations of severe winter storms by initial modification of potential vorticity in sensitive regions. Q. J. R. Meteorol. Soc. 132: 2625-2652.

Røsting B, Kristjánsson JE. 2008. A successful resimulation of the 7-8 January 2005 winter storm through initial potential vorticity modification in sensitive regions. Tellus A 60A: 604-619.

Santurette P, Georgiev CG. 2005. Weather Analysis and Forecasting: Applying satellite water vapor imagery and potential vorticity analysis. Elsevier Academic Press.

Santurette P, Joly A. 2002. ANASYG/PRESYG, Météo-France's new graphical summary of the synoptic situation. Meteorol. Appl. 9: 129-154.

Saunders R, Matricardi M, Brunel P, English S, Bauer P, O'Keefe U, Francis P, Rayer P. 2005. 'RTTOV-8 science and validation report'. NWP SAF Technical report. Met Office: Exeter, UK.

Swarbrick SJ. 2001. Applying the relationship between potential vorticity fields and water vapour imagery to adjust initial conditions in NWP. Meteorol. Appl. 8: 221-228.

Tripoli GJ, Medaglia CM, Dietrich S, Mugnai A, Panegrossi G, Pinori S, Smith, EA. 2005. The 9-10 November 2001 Algerian flood. Bull. Am. Meteorol. Soc. 86: 1229-1235. 